\title{
Culture of Oral Mucosal Epithelial Cells for the Purpose of Treating Limbal Stem Cell Deficiency
}

\author{
Tor Paaske Utheim ${ }^{1,2,3}$, Øygunn Aass Utheim ${ }^{4}$, Qalb-E-Saleem Khan ${ }^{5}$ and Amer Sehic ${ }^{2, *}$ \\ 1 Department of Medical Biochemistry, Oslo University Hospital, Oslo 0407, Norway; utheim2@gmail.com \\ 2 Department of Oral Biology, Faculty of Dentistry, University of Oslo, Oslo 0372, Norway \\ 3 Department of Ophthalmology, Drammen Hospital, Vestre Viken Hospital Trust, Drammen 3004, Norway \\ 4 Department of Ophthalmology, Oslo University Hospital, Oslo 0407, Norway; outheim@gmail.com \\ 5 Department of Medical Biology, Faculty of Health Sciences, University of Tromsø, Tromsø 9037, Norway; \\ qalb-e-saleem.k.ahmed@uit.no \\ * Correspondence: amer.sehic@odont.uio.no; Tel.: +47-22840352
}

Academic Editor: Francesco Puoci

Received: 20 December 2015; Accepted: 22 February 2016; Published: 1 March 2016

\begin{abstract}
The cornea is critical for normal vision as it allows allowing light transmission to the retina. The corneal epithelium is renewed by limbal epithelial cells (LEC), which are located in the periphery of the cornea, the limbus. Damage or disease involving LEC may lead to various clinical presentations of limbal stem cell deficiency (LSCD). Both severe pain and blindness may result. Transplantation of cultured autologous oral mucosal epithelial cell sheet (CAOMECS) represents the first use of a cultured non-limbal autologous cell type to treat this disease. Among non-limbal cell types, CAOMECS and conjunctival epithelial cells are the only laboratory cultured cell sources that have been explored in humans. Thus far, the expression of p63 is the only predictor of clinical outcome following transplantation to correct LSCD. The optimal culture method and substrate for CAOMECS is not established. The present review focuses on cell culture methods, with particular emphasis on substrates. Most culture protocols for CAOMECS used amniotic membrane as a substrate and included the xenogeneic components fetal bovine serum and murine 3T3 fibroblasts. However, it has been demonstrated that tissue-engineered epithelial cell sheet grafts can be successfully fabricated using temperature-responsive culture surfaces and autologous serum. In the studies using different substrates for culture of CAOMECS, the quantitative expression of p63 was generally poorly reported; thus, more research is warranted with quantification of phenotypic data. Further research is required to develop a culture system for CAOMECS that mimics the natural environment of oral/limbal/corneal epithelial cells without the need for undefined foreign materials such as serum and feeder cells.
\end{abstract}

Keywords: cornea; limbal stem cell deficiency; ocular surface disease; oral mucosal epithelial cell sheet; substrates

\section{Introduction}

\subsection{Limbal Stem Cell Deficiency}

The regenerating organs in the body (e.g., cornea, skin, and gut) harbor tissue-specific stem cells, which are responsible for tissue homeostasis and efficient healing in case of injury. The ocular surface is composed of corneal and conjunctival epithelium [1]. The corneal epithelium in particular plays a crucial role in maintaining the cornea's avascularity and transparency [2]. The self-renewal of the corneal surface is a multistep process dependent on a small population of limbal stem cells $[3,4]$ located in structures referred to as limbal crypts [5] or limbal epithelial crypts [6]. 
Numerous external factors and disorders (e.g., chemical or thermal injuries, microbial infections, surgeries involving the limbus, cicatricial pemphigoid, and aniridia) can lead to dysfunction or loss of limbal epithelial cells (LEC), resulting in either partial or total limbal stem cell deficiency (LSCD) [2]. The condition can be painful and may lead to reduced vision, or even blindness, by causing persistent epithelial defects, fibrovascular pannus, conjunctivalization, and superficial and deep vascularization of the cornea. The persistence of epithelial defects may result in ulceration, scarring, and corneal perforation [2]. Limbal stem cell deficiency is most often bilateral.

\subsection{Treatment Strategies for Limbal Stem Cell Deficiency}

Treatment approaches for LSCD can be categorized as follows: (a) transplantation of cultured cells [2]; (b) transplantation of non-cultured cells [2]; and (c) approaches that do not involve transplantation of cells, for example keratoprostheses [7]. A great variety of cell-based therapeutic strategies have been suggested for LSCD [8]. The stem cells of the corneal epithelium are believed to be located in the limbus [3,4]. In 1989, limbal grafts were transplanted to eyes suffering from LSCD to restore the corneal surface [9]. The results were promising. However, the procedure carries a risk of inducing LSCD in the healthy eye because of large limbal cell withdrawal [10], and the therapy is not possible in cases of bilateral LSCD. This led to a novel therapeutic strategy with ex vivo expansion of LEC first reported by Pellegrini and colleagues in 1997 [11]. In their study, successful ocular surface reconstruction was achieved using autologous cultivated LEC isolated from small biopsies in two patients, both affected with severe unilateral ocular surface disease. Since then, more than 1000 patients suffering from LSCD have been treated with ex vivo cultured LEC [11-18]. Since 2003, nine cultured non-limbal cell sources have been successfully used to reconstruct the corneal epithelium in bilateral LSCD, in which limbal tissue is not recommended for harvest [8]. The sources include oral mucosal epithelial cells [19], embryonic stem cells [20], conjunctival epithelial cells [21], epidermal stem cells [22], dental pulp stem cells [23], bone marrow-derived mesenchymal stem cells [24], hair follicle bulge-derived stem cells [25], umbilical cord lining stem cells [26], and orbital fat-derived stem cells [27]. Among non-limbal cell types, cultured autologous oral mucosal epithelial cell sheet (CAOMECS) and conjunctival epithelial cells are the only laboratory cultured cell sources that have been explored in humans.

\section{Cultured Autologous Oral Mucosal Epithelial Cell Sheet}

A significant advantage of CAOMECS as a cell source is easy isolation from biopsies that heal quickly without residual scarring. As the CAOMECS are autologous, there is no risk of immune rejection, thus making immunosuppression unnecessary. However, a disadvantage of transplantation of CAOMECS is the development of peripheral neovascularization [28-31]. Studies have demonstrated that angiogenesis related factors were expressed in corneas after transplantation [32-35]. Anti-angiogenic therapy has been proposed as a method to prevent corneal neovascularization and improve the outcomes after transplantation with CAOMECS [36]. Thus far, 242 patients with LSCD have been reported as treated, with a success rate of $72 \%$ and a follow-up time of between one and 7.5 years [19,28-32,37-51].

An ideal substrate is easily available, transparent, and easy to manipulate; it permits cells to proliferate and retain high viability. Though transplant success has been demonstrated using various culture methods, the optimal culture method for CAOMECS for use in corneal regeneration has not been established. The determination of appropriate substrates and culture protocols for CAOMECS may contribute to the development of standardized, safe, and effective regenerative therapy for LSCD. The present review focuses on the current state of knowledge of the culture methods and substrates used for CAOMECS in ocular regeneration. The review was prepared by searching the National Library of Medicine database using the search term "oral mucosal epithelial cells" in an attempt not to leave out any relevant publications. In total, the search resulted in 4897 studies, of which 41 studies, published from 2003 to 2015, were related directly to the core topic of the present review. 


\section{Characteristics of the Culture Protocol for Cultured Autologous Oral Mucosal Epithelial Cell Sheet}

The standard culture conditions used for production of transplantable epithelial cell sheets, including CAOMECS, typically requires fetal bovine serum (FBS) and murine 3T3 feeder layers [52]. The epithelial progenitor or stem cells isolated from small biopsies can, under these conditions, be expanded in vitro to create stratified epithelial layers that closely resemble native tissues [53]. However, these constructs are classified as xenogeneic products, with the inherent possibility of infection or pathogen transmission from animal-derived materials [54]. In addition, xeno-contamination may result in immunogenicity [55]. The use of feeder layers and foreign serum is, therefore, a concern in regenerative medicine. Furthermore, dispase, a bacteria-derived protease, is commonly used to enable cell isolation [53].

Treatment of LSCD based on various methods using CAOMECS is presented in Figure 1. The following culture methods and substrates have been used in order to produce transplantable CAOMECS: (1) amniotic membrane [28-30,32,35,37,39,40,42,43,45-47,49,51,56-63] (Table 1); (2) temperature-responsive cell-culture surfaces [31,38,64-70] (Table 2); (3) fibrin-coated culture plates [41,48] (Table 3); (4) fibrin gel [71] (Table 3); (5) collagen IV-coated culture plates [72] (Table 3); and (6) culture plates without any substrate $[33,34,73,74]$ (Table 3).

The possibility of pathogen transmission cannot be excluded from xenogeneic or allogeneic materials, such as human amniotic membrane obtained following elective Caesarean operations [17,18,75], collagen isolated from porcine or bovine skin [76], and hydrated gels made from fibrin derived from human donor blood [77-79]. Therefore, the establishment of culture conditions avoiding animal-derived products and foreign undefined components is warranted.

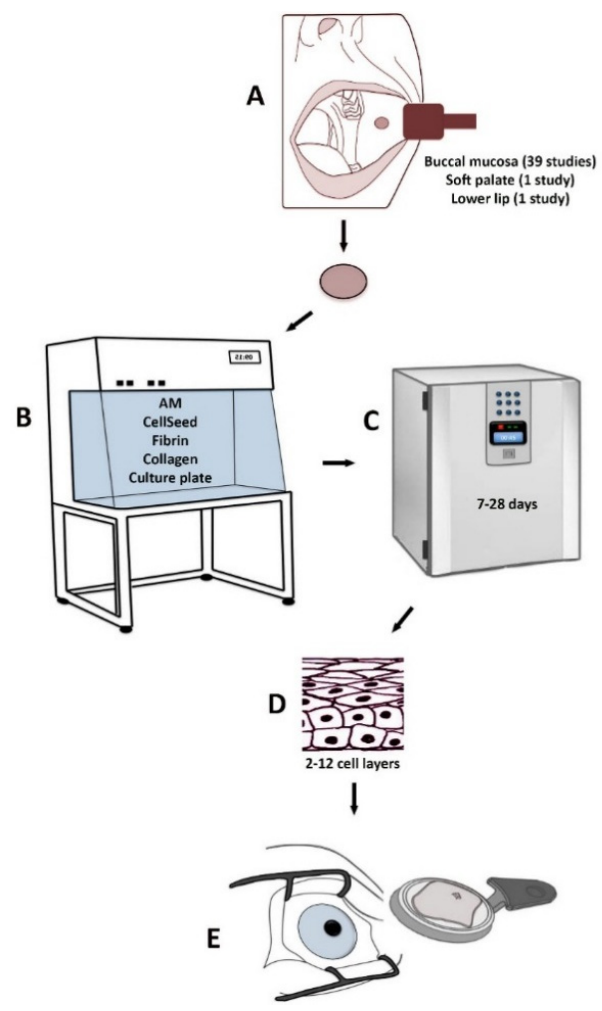

Figure 1. Treatment of LSCD based on various methods using CAOMECS. A biopsy from the mucosa is harvested from the oral cavity (A). The biopsy is cultured in the laboratory on different substrates (B) for 7-28 days (C). A stratified cultured tissue is produced (D) and is transplanted to the diseased eye $(\mathbf{E})$. 
Table 1. Culture of oral mucosal epithelial cells on amniotic membrane.

\begin{tabular}{|c|c|c|c|c|c|c|c|c|c|c|}
\hline Author, Year & Type of Study & $\begin{array}{c}\text { Cell } \\
\text { Suspension/Explant }\end{array}$ & Substrate & Air-Lifting & Serum & 3Т3 & Culture Medium & $\begin{array}{c}\text { Culture Time } \\
\text { (Days) }\end{array}$ & Morphology & Phenotype \\
\hline $\begin{array}{l}\text { Shimazaki et al., } \\
2009[62]\end{array}$ & Animal & Cell suspension & Denuded AM & Yes & FBS & Yes & SHEM (aprotinin) & $7-10$ & $\begin{array}{l}\text { Multilayered } \\
\text { stratified } \\
\text { epithelium; } \\
\text { Tight junctions }\end{array}$ & $\begin{array}{l}\text { Expression of } \mathrm{K} 3, \mathrm{ZO}-1, \\
\text { and occludin }\end{array}$ \\
\hline $\begin{array}{l}\text { Sekiyama et al., } \\
2006[35]\end{array}$ & in Vitro & Cell suspension & Denuded AM & Yes & - & Yes & $\begin{array}{l}\text { DMEM:F12 (penicillin, } \\
\text { streptomycin, insulin, } \\
\text { cholera toxin, EGF) }\end{array}$ & $7-14$ & - & $\begin{array}{l}\text { Expression of VEGF and } \\
\text { Flt-1; Low expression } \\
\text { of PEDF }\end{array}$ \\
\hline $\begin{array}{l}\text { Sotozono et al., } \\
2013[50]\end{array}$ & Clinical & Cell suspension & Denuded AM & Yes & HAS & Yes & $\begin{array}{l}\text { DMEM:F12 (penicillin, } \\
\text { streptomycin, insulin, } \\
\text { cholera toxin, EGF) }\end{array}$ & $8-9$ & - & - \\
\hline $\begin{array}{l}\text { Sotozono et al., } \\
\quad 2014[49]\end{array}$ & Clinical & Cell suspension & Denuded AM & Yes & HAS & Yes & $\begin{array}{l}\text { DMEM:F12 (penicillin, } \\
\text { streptomycin, insulin, } \\
\text { cholera toxin, EGF) }\end{array}$ & $8-9$ & - & - \\
\hline $\begin{array}{l}\text { Gaddipati et al., } \\
\quad 2014[40]\end{array}$ & Clinical & Explant & Denuded AM & - & - & No & $\begin{array}{l}\text { DMEM:F12 (penicillin, } \\
\text { streptomycin, insulin, } \\
\text { cholera toxin, EGF) }\end{array}$ & 9 & $\begin{array}{l}\text { 5-6 cell layers; } \\
\text { Stratified } \\
\text { epithelium }\end{array}$ & $\begin{array}{c}\text { Expression of K3, K12, } \\
\text { K19, Ki-67, p75, and PAX6 } \\
\text { p63 expression in most of } \\
\text { the basal and } \\
\text { supra basal cells }\end{array}$ \\
\hline $\begin{array}{l}\text { Sen et al., } \\
2011 \text { [00] }\end{array}$ & in Vitro & Explant & Denuded AM & Yes & FCS & Yes & $\begin{array}{l}\text { DMEM:F12 (penicillin, } \\
\text { streptomycin, } \\
\text { amphotericin, EGF, } \\
\text { insulin) }\end{array}$ & 14 & $\begin{array}{c}\text { Stratified } \\
\text { epithelium; } \\
\text { Desmosomes; } \\
\text { Abundant mucin } \\
\text { granules }\end{array}$ & $\begin{array}{l}\text { Expression of K3, K4, K13, } \\
\text { connexin } 43, \mathrm{p} 63, \mathrm{p} 75, \\
\beta_{1}-\text { integrin, CD29, } \\
\text { ABCG2, and MUC 1, } \\
13,15 \text { and } 16\end{array}$ \\
\hline $\begin{array}{l}\text { Satake et al., } \\
2008[47]\end{array}$ & Clinical & Cell suspension & Denuded AM & Yes & FBS & Yes & $\begin{array}{l}\text { DMEM:F12 (gentamycin, } \\
\text { streptomycin, penicillin, } \\
\text { amphotericin, } \\
\text { EGF, insulin) }\end{array}$ & $>14$ & $\begin{array}{c}\text { Non-keratinized, } \\
\text { squamous, } \\
\text { polygonal, cells } \\
\text { with a low nuclear } \\
\text { to cytoplasmatic } \\
\text { ratio }\end{array}$ & - \\
\hline $\begin{array}{l}\text { Takeda et al., } \\
2011 \text { [51] }\end{array}$ & Clinical & Cell suspension & Denuded AM & Yes & - & Yes & $\begin{array}{l}\text { DMEM:F12 (penicillin, } \\
\text { streptomycin, insulin, } \\
\text { cholera toxin, EGF) }\end{array}$ & $14-16$ & - & - \\
\hline $\begin{array}{l}\text { Chen et al., } \\
2009 \text { [39] }\end{array}$ & Clinical & Cell suspension & Denuded AM & No & FCS & Yes & $\begin{array}{l}\text { DMEM:F12(penicillin, } \\
\text { streptomycin, insulin, } \\
\text { cholera toxin, EGF) }\end{array}$ & $14-21$ & $\begin{array}{l}2-5 \text { cell layers; } \\
\text { Elongated cell } \\
\text { nuclei }\end{array}$ & $\begin{array}{c}\text { Expression of K3, K4, K13, } \\
\text { p63, p75, and ABCG2 }\end{array}$ \\
\hline $\begin{array}{l}\text { Chen et al., } \\
2012 \text { [32] }\end{array}$ & Clinical & Cell suspension & Denuded AM & No & FCS & Yes & $\begin{array}{l}\text { SHEM (penicillin, } \\
\text { streptomycin, insulin, } \\
\text { cholera toxin, EGF) }\end{array}$ & $14-21$ & $\begin{array}{l}\text { 5-10 cell layers; } \\
\text { Stratified } \\
\text { epithelium }\end{array}$ & $\begin{array}{l}\text { Expression of FGF2, K8, } \\
\text { VEGF, endostatin, PEDF, } \\
\text { and IL-1ra }\end{array}$ \\
\hline $\begin{array}{l}\text { Ma et al., } \\
2009 \text { [29] }\end{array}$ & Clinical & Suspension & Denuded AM & No & FBS & Yes & $\begin{array}{l}\text { DMEM:F12 (penicillin, } \\
\text { streptomycin, insulin, } \\
\text { cholera toxin, EGF) }\end{array}$ & $14-21$ & $\begin{array}{l}2-5 \text { cell layers; } \\
\text { Elongated cell } \\
\text { nuclei }\end{array}$ & $\begin{array}{l}\text { Expression of K3, K13, } \\
\text { p63, p75, and ABCG2 }\end{array}$ \\
\hline $\begin{array}{l}\text { Nakamura et al., } \\
\quad 2004[30]\end{array}$ & Clinical & Cell suspension & Denuded AM & Yes & FBS & Yes & $\begin{array}{l}\text { DMEM:F12 (penicillin, } \\
\text { streptomycin, insulin, } \\
\text { cholera toxin, EGF) }\end{array}$ & $14-21$ & $\begin{array}{l}\text { 5-6 cell layers; } \\
\text { Desmosomes and } \\
\text { hemidesmosomes }\end{array}$ & $\begin{array}{l}\text { Expression of K3, K4, } \\
\text { and K13 }\end{array}$ \\
\hline
\end{tabular}


Table 1. Cont.

\begin{tabular}{|c|c|c|c|c|c|c|c|c|c|c|}
\hline Author, Year & Type of Study & $\begin{array}{c}\text { Cell } \\
\text { Suspension/Explant }\end{array}$ & Substrate & Air-Lifting & Serum & $3 \mathrm{~T} 3$ & Culture Medium & $\begin{array}{c}\text { Culture Time } \\
\text { (Days) }\end{array}$ & Morphology & Phenotype \\
\hline $\begin{array}{l}\text { Ang et al., } \\
2006 \text { [37] }\end{array}$ & Clinical & Cell suspension & Denuded AM & Yes & HAS/FBS & Yes & $\begin{array}{l}\text { KGM (penicillin, } \\
\text { streptomycin, } \\
\text { insulin, EGF) }\end{array}$ & $15-16$ & $\begin{array}{l}\text { 4-6 cell layers; } \\
\text { Cuboidal cells, } \\
\text { More flattened cells } \\
\text { superficially }\end{array}$ & $\begin{array}{l}\text { Expression of } \mathrm{K} 3, \mathrm{~K} 4, \mathrm{~K} 13 \\
\text { ZO-1, desmoplakin, } \\
\text { integrin- } \alpha_{1} \text {, laminin } 5, \\
\text { and collagen IV }\end{array}$ \\
\hline $\begin{array}{l}\text { Ang et al., } \\
2006 \text { [37] }\end{array}$ & Clinical & Cell suspension & Denuded AM & Yes & HAS/FBS & Yes & $\begin{array}{l}\text { KGM (penicillin, } \\
\text { streptomycin, } \\
\text { insulin, EGF) }\end{array}$ & $15-16$ & $\begin{array}{l}\text { 4-6 cell layers; } \\
\text { Cuboidal cells, } \\
\text { More flattened cells } \\
\text { superficially }\end{array}$ & $\begin{array}{l}\text { Expression of } \mathrm{K} 3, \mathrm{~K} 4, \mathrm{~K} 13 \\
\text { ZO-1, desmoplakin, } \\
\text { integrin- } \alpha_{1} \text {, laminin } 5, \\
\text { and collagen IV }\end{array}$ \\
\hline $\begin{array}{l}\text { Inatomi et al., } \\
2006[28]\end{array}$ & Clinical & Cell suspension & Denuded AM & Yes & FCS & Yes & $\begin{array}{l}\text { DMEM:F12 (penicillin, } \\
\text { streptomycin, insulin, } \\
\text { cholera toxin, EGF) }\end{array}$ & $15-16$ & $\begin{array}{c}\text { 5-6 cell layers; } \\
\text { Cuboidal cells, } \\
\text { several suprabasal } \\
\text { cell layers, and flat } \\
\text { apical cell layers }\end{array}$ & $\begin{array}{l}\text { Expression of VEGF, FGF, } \\
\text { and thrombospondin } 1\end{array}$ \\
\hline $\begin{array}{l}\text { Inatomi et al., } \\
2006[28]\end{array}$ & Clinical & Cell suspension & Denuded AM & Yes & FCS & Yes & $\begin{array}{l}\text { DMEM:F12 (penicillin, } \\
\text { streptomycin, insulin, } \\
\text { cholera toxin, EGF) }\end{array}$ & $15-16$ & $\begin{array}{c}\text { 5-6 cell layers; } \\
\text { Cuboidal cells, } \\
\text { several suprabasal } \\
\text { cell layers, and flat } \\
\text { apical cell layers }\end{array}$ & $\begin{array}{l}\text { Expression of VEGF, FGF, } \\
\text { and thrombospondin } 1\end{array}$ \\
\hline $\begin{array}{l}\text { Inatomi et al., } \\
2006[42]\end{array}$ & Clinical & Cell suspension & Denuded AM & Yes & HAS/FCS & Yes & $\begin{array}{l}\text { DMEM:F12 (penicillin, } \\
\text { streptomycin, insulin, } \\
\text { cholera toxin, EGF) }\end{array}$ & $15-16$ & $\begin{array}{c}\text { 5-6 cell layers; } \\
\text { Cuboidal cells, } \\
\text { several suprabasal } \\
\text { cell layers, and flat } \\
\text { apical cell layers }\end{array}$ & \\
\hline $\begin{array}{l}\text { Nakamura et al., } \\
2011 \text { [45] }\end{array}$ & Clinical & Cell suspension & Denuded AM & Yes & HAS & Yes & $\begin{array}{l}\text { KGM (penicillin, } \\
\text { streptomycin, insulin, } \\
\text { cholera toxin, EGF) }\end{array}$ & $15-16$ & - & - \\
\hline $\begin{array}{l}\text { Priya et al., } \\
2011[46]\end{array}$ & Clinical & Cell suspension & Denuded AM & No & AS & Yes & $\begin{array}{l}\text { DMEM:F12 (PI, mouse } \\
\text { IgG1/IgG2a, mitomycin } \\
\text { C, EGF, insulin, } \\
\text { penicillin, streptomycin) }\end{array}$ & $18-21$ & $\begin{array}{l}\text { Flat and uniformly } \\
\text { distributed } \\
\text { epithelial cells }\end{array}$ & $\begin{array}{l}\text { Low expression of } \mathrm{p} 63 \\
(3.0 \% \pm 1.7 \% \text { of cells); } \\
\text { Negative expression } \\
\text { of K12 }\end{array}$ \\
\hline $\begin{array}{l}\text { Sharma et al., } \\
2011 \text { [61] }\end{array}$ & In vitro & Cell suspension & Denuded AM & - & FBS & Yes & $\begin{array}{l}\text { DMEM:F12 (penicillin, } \\
\text { streptomycin, insulin, } \\
\text { cholera toxin, EGF) }\end{array}$ & 21 & $\begin{array}{l}3-5 \text { cell layers; } \\
\text { Stratified } \\
\text { epithelium }\end{array}$ & $\begin{array}{c}\text { Expression of K3 and } \\
\beta_{1} \text {-integrin; High } \\
\text { expression of p63 }\end{array}$ \\
\hline $\begin{array}{c}\text { Promprasit et al., } \\
2014[59]\end{array}$ & in Vitro & Explant & Denuded AM & Yes & FBS & Yes & $\begin{array}{l}\text { DMEM:F12 (penicillin, } \\
\text { streptomycin, } \\
\text { insulin, EGF) }\end{array}$ & 21 & $\begin{array}{l}2-5 \text { cell layers; } \\
\text { Stratified } \\
\text { epithelium; } \\
\text { Cuboidal cells in } \\
\text { basal layer, flat } \\
\text { superficial cells }\end{array}$ & $\begin{array}{l}\text { Expression of K3 and } \\
\text { connexin 43; High } \\
\text { expression of p63 }\end{array}$ \\
\hline $\begin{array}{l}\text { Nakamura et al., } \\
2003 \text { [57] }\end{array}$ & Animal & Cell suspension & Denuded AM & Yes & FBS & Yes & $\begin{array}{l}\text { DMEM:F12 (penicillin, } \\
\text { streptomycin, insulin, } \\
\text { cholera toxin, EGF) }\end{array}$ & 21 & $\begin{array}{l}\text { 3-5 cell layers; } \\
\text { Stratified } \\
\text { epithelium; }\end{array}$ & $\begin{array}{l}\text { Expression of K3, K4, } \\
\text { and K13 }\end{array}$ \\
\hline
\end{tabular}


Table 1. Cont

\begin{tabular}{|c|c|c|c|c|c|c|c|c|c|c|}
\hline Author, Year & Type of Study & $\begin{array}{c}\text { Cell } \\
\text { Suspension/Explant }\end{array}$ & Substrate & Air-Lifting & Serum & $3 \mathrm{~T} 3$ & Culture Medium & $\begin{array}{c}\text { Culture Time } \\
\text { (Days) }\end{array}$ & Morphology & Phenotype \\
\hline $\begin{array}{l}\text { Nakamura et al., } \\
2003[58]\end{array}$ & Animal & Cell suspension & Denuded AM & Yes & FBS & Yes & $\begin{array}{l}\text { DMEM:F12 (penicillin, } \\
\text { streptomycin, insulin, } \\
\text { cholera toxin, EGF) }\end{array}$ & 21 & $\begin{array}{l}\text { 5-6 cell layers; } \\
\text { Stratified } \\
\text { epithelium; }\end{array}$ & $\begin{array}{l}\text { Expression of K3, K4, } \\
\text { and K13 }\end{array}$ \\
\hline $\begin{array}{l}\text { Nakamura et al., } \\
2003[58]\end{array}$ & Animal & Cell suspension & Denuded AM & Yes & FBS & Yes & $\begin{array}{l}\text { DMEM:F12 (penicillin, } \\
\text { streptomycin, insulin, } \\
\text { cholera toxin, EGF) }\end{array}$ & 21 & $\begin{array}{l}\text { 5-6 cell layers; } \\
\text { Stratified } \\
\text { epithelium; }\end{array}$ & $\begin{array}{l}\text { Expression of K3, K4, } \\
\text { and } \mathrm{K} 13\end{array}$ \\
\hline $\begin{array}{l}\text { Kolli et al., } \\
2014 \text { [43] }\end{array}$ & Clinical & Explant & Intact AM & Yes & HAS & No & $\begin{array}{l}\text { DMEM:F12 (penicillin, } \\
\text { streptomycin, insulin, } \\
\text { cholera toxin, EGF, } \\
\text { hydrocortisone, } \\
\text { triiiodothyronine, } \\
\text { adenine) }\end{array}$ & 21 & $\begin{array}{l}\text { 3-7 cell layers, } \\
\text { firmly attached to } \\
\text { each other; High } \\
\text { nucleus to } \\
\text { cytoplasm ratio }\end{array}$ & $\begin{array}{l}\text { Expression of K3, ABCG2, } \\
\text { and C/EBP ; High } \\
\text { expression of } \triangle \mathrm{Np} 63 \alpha ; \\
\text { Negative for K12 } \\
\text { and PAX6 }\end{array}$ \\
\hline $\begin{array}{l}\text { Madhira et al., } \\
2008[56]\end{array}$ & in Vitro & Cell suspension & Denuded AM & No & FCS & No & $\begin{array}{l}\text { DMEM:F12 (penicillin, } \\
\text { streptomycin, } \\
\text { amphotericin, } \\
\text { gentamycin, insulin, } \\
\text { cholera toxin, EGF) }\end{array}$ & $21-28$ & $\begin{array}{l}\text { 2-3 cell layers; } \\
\text { Stratified } \\
\text { epithelium; Gap } \\
\text { junctions and } \\
\text { desmosomes }\end{array}$ & $\begin{array}{l}\text { Expression of K3, K4, K15, } \\
\text { and connexin 43; Negative } \\
\text { for K12 and PAX } 6\end{array}$ \\
\hline $\begin{array}{l}\text { Yokoo et al., } \\
2006 \text { [63] }\end{array}$ & in Vitro & Cell suspension & Denuded AM & Yes & FBS & Yes & $\begin{array}{l}\text { DMEM/F12 (penicillin, } \\
\text { streptomycin, } \\
\text { amphotericin) }\end{array}$ & 28 & $\begin{array}{l}\text { 3-5 cell layers; } \\
\text { Stratified } \\
\text { epithelium }\end{array}$ & - \\
\hline
\end{tabular}

ABCG2, ATP binding cassette subfamily G member; AM, amniotic membrane; AS, autologous serum; DMEM, Dulbecco's modified eagle medium; EGF, epidermal growth factor; FBS, fetal bovine serum; FCS, fetal calf serum; FGF2, fibroblast growth factor 2; Flt-1, Fms-like tyrosine kinase 1; HAS, human autologous serum; IgG2a, immunoglobulin G2a; IL-1ra, interleukin 1ra; KGM, keratinocyte growth medium; MUC, mucin; PAX6, paired box 6; PEDF, pigment epithelium derived factor; PI, propidium iodide; SHEM, supplemented hormonal epithelial medium; VEGF, vascular endothelial growth factor; ZO-1, zona occludens protein 1;-, indicates not reported. 
Table 2. Culture of oral mucosal epithelial cells on temperature-responsive surfaces.

\begin{tabular}{|c|c|c|c|c|c|c|c|c|c|c|}
\hline Author, Year & Type of Study & $\begin{array}{c}\text { Cell } \\
\text { Suspension/Explant } \\
\end{array}$ & Substrate & Air-Lifting & Serum & $3 \mathrm{~T} 3$ & Culture Medium & $\begin{array}{c}\begin{array}{c}\text { CultureTime } \\
\text { (Days) }\end{array} \\
\end{array}$ & Morphology & Phenotype \\
\hline $\begin{array}{l}\text { Burillon et al., } \\
2012 \text { [38] }\end{array}$ & Clinical & Cell suspension & CellSeed ${ }^{a}$ & No & - & Yes & - & - & $\begin{array}{l}\text { Similar characteristics } \\
\text { to normal corneal } \\
\text { epithelium; Basal } \\
\text { membrane }\end{array}$ & $\begin{array}{c}\text { Expression of K3/76, } \\
\text { p63, laminin } 5, \text { and } \\
\beta_{1} \text {-integrin }\end{array}$ \\
\hline $\begin{array}{l}\text { Soma et al., } \\
2014 \text { [69] }\end{array}$ & Animal & Cell suspension & CellSeed ${ }^{a}$ & - & FBS & Yes & $\begin{array}{c}\text { DMEM:F12 } \\
\text { (insulin, } \\
\text { triiodthronine, } \\
\text { hydrocortisone) }\end{array}$ & $10-12$ & $\begin{array}{l}\text { 3-4 cell layers; } \\
\text { Stratified epithelium; } \\
\text { Cobble stone-like cell } \\
\text { morphology }\end{array}$ & $\begin{array}{c}\text { Expression } \\
\text { of K14 and p63 }\end{array}$ \\
\hline $\begin{array}{l}\text { Sugiyama et al., } \\
2014[70]\end{array}$ & Animal & Cell suspension & CellSeed $^{\mathrm{a}}$ & - & FBS & Yes & $\begin{array}{c}\text { DMEM:F12 } \\
\text { (penicillin, } \\
\text { streptomycin, } \\
\text { insulin, cholera } \\
\text { toxin, EGF, } \\
\text { hydrocortisone, } \\
\text { triodothyronine) } \\
\end{array}$ & 14 & $\begin{array}{l}3-5 \text { cell layers; } \\
\text { Stratified epithelium; } \\
\text { Cuboidal cells in the } \\
\text { basal layer, squamous } \\
\text { epithelium on the } \\
\text { apical side }\end{array}$ & $\begin{array}{l}\text { Expression of K4, } \\
\text { K13, MUC5 }\end{array}$ \\
\hline $\begin{array}{l}\text { Nishida et al., } \\
2004 \text { [31] }\end{array}$ & Clinical & Cell suspension & CellSeed ${ }^{a}$ & No & - & Yes & - & 14 & $\begin{array}{l}\text { Multilayered cell } \\
\text { sheets; Microvilli, } \\
\text { desmosomes, } \\
\text { basement membrane }\end{array}$ & $\begin{array}{c}\text { Expression of } \\
\beta_{1} \text {-integrin, } \\
\mathrm{K} 3 \text {, and p63 }\end{array}$ \\
\hline $\begin{array}{l}\text { Bardag-Gorce } \\
\text { et al., 2015 [64] }\end{array}$ & Animal & Cell suspension & CellSeed ${ }^{a}$ & - & FBS & Yes & - & 14 & $\begin{array}{l}\text { Multilayered stratified } \\
\text { epithelium }\end{array}$ & $\begin{array}{c}\text { Expression of K4, } \\
\Delta \mathrm{Np} 63, \mathrm{TIMP}-1, \\
\text { TIMP-3, } \\
\text { and connexin } 43\end{array}$ \\
\hline $\begin{array}{l}\text { Hayashida et al., } \\
2005 \text { [66] }\end{array}$ & Animal & Cell suspension & CellSeed ${ }^{a}$ & - & FBS & Yes & - & 14 & $\begin{array}{l}3-5 \text { cell layers; } \\
\text { Stratified epithelium; }\end{array}$ & $\begin{array}{l}\text { Expression of K3, K4, } \\
\text { K13, p63, } \Delta \mathrm{Np} 63 \text {, and } \\
\beta_{1} \text {-integrin }\end{array}$ \\
\hline $\begin{array}{l}\text { Murakami et al., } \\
\quad 2006[67]\end{array}$ & in Vitro & Cell suspension & CellSeed $^{a}$ & - & HAS & No & $\begin{array}{c}\text { DMEM/F12 } \\
\text { (penicillin, } \\
\text { streptomycin, } \\
\text { fungizone, } \\
\text { transferrin, EGF, } \\
\text { cholera toxin, } \\
\text { hydrocortisone, } \\
\text { triiodothyronine) }\end{array}$ & 14 & $\begin{array}{l}\text { 3-5 cell layers; } \\
\text { Cuboidal basal cells, } \\
\text { flattened middle cells, } \\
\text { and polygonal } \\
\text { flattened } \\
\text { superficial cells }\end{array}$ & $\begin{array}{l}\text { Expression of } \\
\text { p63 and Ki67 }\end{array}$ \\
\hline $\begin{array}{l}\text { Oie et al., } \\
2010[68]\end{array}$ & Clinical & Cell suspension & CellSeed ${ }^{a}$ & - & HAS & Yes & - & $14-17$ & $\begin{array}{l}\text { 4-5 cell layers; Small } \\
\text { basal cells, flattened } \\
\text { middle cells, and } \\
\text { polygonal flattened } \\
\text { superficial cells }\end{array}$ & $\begin{array}{l}\text { Expression of K1, } \\
\text { K3/76, K4, K10, K12, } \\
\text { K13, K15, ZO-1, and } \\
\text { MUC16; Moderate } \\
\text { expression of p63 } \\
\text { (30.7\% } \pm 7.6 \% \text { of cells) }\end{array}$ \\
\hline
\end{tabular}


Table 3. Culture of oral mucosal epithelial cells on other substrates.

\begin{tabular}{|c|c|c|c|c|c|c|c|c|c|c|}
\hline Author, Year & Type of Study & $\begin{array}{c}\text { Cell } \\
\text { Suspension/Explant }\end{array}$ & Substrate & Air-Lifting & Serum & $3 \mathrm{~T} 3$ & Culture Medium & $\begin{array}{c}\text { Culture Time } \\
\text { (Days) }\end{array}$ & Morphology & Phenotype \\
\hline $\begin{array}{l}\text { Satake et al., } \\
2011[48]\end{array}$ & Clinical & Cell suspension & $\begin{array}{l}\text { Fibrin-coated cell } \\
\text { culture inserts }\end{array}$ & Yes & HAS & Yes & $\begin{array}{l}\text { DMEM:F12 (penicillin, } \\
\text { streptomycin, transferrin, } \\
\text { EGF, hydrocortisone, } \\
\text { triiodothyronine) }\end{array}$ & - & 5-6 cell layers; & - \\
\hline $\begin{array}{l}\text { Hirayama et al., } \\
\quad 2012[41]\end{array}$ & Clinical & Cell suspension & $\begin{array}{l}\text { Fibrin-coated cell } \\
\text { culture inserts }\end{array}$ & Yes & HAS & Yes & $\begin{array}{l}\text { DMEM:F12 (penicillin, } \\
\text { streptomycin, insulin, } \\
\text { EGF, hydrocortisone) }\end{array}$ & - & 5-6 cell layers; & - \\
\hline $\begin{array}{l}\text { Sheth et al., } \\
2014 \text { [71] }\end{array}$ & in Vitro & Explant & Fibrin gel & - & FCS & No & $\begin{array}{l}\text { DMEM:F12 (penicillin, } \\
\text { cholera toxin, insulin, } \\
\text { EGF, hydrocortisone) }\end{array}$ & - & $\begin{array}{l}\text { Multilayered } \\
\text { epithelium; } \\
\text { Cobblestone } \\
\text { morphology }\end{array}$ & $\begin{array}{l}\text { Expression of K3, } \\
\text { K13, and K19; } \\
\text { High expression } \\
\text { of p } 63\end{array}$ \\
\hline $\begin{array}{l}\text { Ilmarinen et al. } \\
2012[72]\end{array}$ & in Vitro & Cell suspension & $\begin{array}{l}\text { Collagen } \\
\text { IV-coated cell } \\
\text { culture inserts }\end{array}$ & Yes & No & No & $\begin{array}{l}\text { Serum-free oral PCT } \\
\text { epithelium } \\
\text { medium (EGF) }\end{array}$ & $13-17$ & $\begin{array}{l}\text { 4-12 cell layers; } \\
\text { Stratified epithelium; } \\
\text { Cuboidal basal cells } \\
\text { and flat intermediate } \\
\text { and superficial cells }\end{array}$ & $\begin{array}{l}\text { Expression of } \\
\text { K3/12, K4, K13, } \\
\text { Ki67, and p63 }\end{array}$ \\
\hline $\begin{array}{l}\text { Kanayama et al., } \\
2007[34]\end{array}$ & in Vitro & Cell suspension & Culture plate & - & FBS & Yes & $\begin{array}{l}\text { DMEM (Supplements } \\
\text { not reported) }\end{array}$ & - & $\begin{array}{l}\text { Multilayered cells; } \\
\text { Normal epithelial } \\
\text { morphology }\end{array}$ & $\begin{array}{l}\text { Expression of } \\
\text { FGF2, VEGF, } \\
\text { Ang1, and } \\
\text { TGF- } \beta 1\end{array}$ \\
\hline $\begin{array}{l}\text { Kanayama et al., } \\
2009 \text { [33] }\end{array}$ & in Vitro & Cell suspension & Culture plate & - & FBS & Yes & $\begin{array}{l}\text { DMEM (Supplements } \\
\text { not reported) }\end{array}$ & 14 & Multilayered cells & $\begin{array}{l}\text { Expression of } \\
\text { VEGFr-1 }\end{array}$ \\
\hline $\begin{array}{l}\text { Hyun et al., } \\
2014[74]\end{array}$ & Animal & Cell suspension & Culture plate & - & FBS & Yes & $\begin{array}{l}\text { DMEM:F12 (penicillin, } \\
\text { streptomycin, } \\
\text { gentamycin, } \\
\text { amphotericin) }\end{array}$ & 14 & $\begin{array}{c}2-6 \text { cell layers; } \\
\text { Stratified epithelium }\end{array}$ & $\begin{array}{c}\text { Expression of K3, } \\
\text { K4, and Ki67; } \\
\text { High expression } \\
\text { of p63 }\end{array}$ \\
\hline $\begin{array}{l}\text { Krishnan et al. } \\
\quad 2010 \text { [73] }\end{array}$ & in Vitro & Explant & Culture plate & - & FBS & - & $\begin{array}{c}\text { DMEM:F12 } \\
\text { (streptomycin, } \\
\text { amphotericin, EGF, } \\
\text { insulin, transferrin, } \\
\text { selenium, } \\
\text { hydrocortisone) }\end{array}$ & 21 & $\begin{array}{l}\text { Multilayered cells; } \\
\text { Normal epithelial } \\
\text { morphology }\end{array}$ & $\begin{array}{c}\text { Expression of } \\
\text { ABCG2, K3, } \\
\text { MUC1/4/16, } \\
\text { hBD1/2,3; High } \\
\text { expression of p63 } \\
\text { and } \Delta \mathrm{Np} 63\end{array}$ \\
\hline
\end{tabular}

ABCG2, ATP binding cassette subfamily G member; Ang1, angiopoietin; DMEM, Dulbecco's modified eagle medium; EGF, epidermal growth factor; FBS, fetal bovine serum; FCS, fetal calf serum; FGF2, fibroblast growth factor 2; HAS, human autologous serum; hBD, human beta defensing; MUC, mucin; PCT, progenitor cell-targeted; TGF- $\beta 1$, transforming growth factor beta 1; VEGF, vascular endothelial growth factor; -, indicates not reported. 


\section{Culture of Oral Mucosal Epithelial Cells on Amniotic Membrane}

Amniotic membrane has been used on the ocular surface since 1940 [80], and for the first time in treatment of LSCD in 1946 [81]. In cases of partial LSCD, amniotic membrane can be applied to the affected eye and provide a suitable substrate for corneal epithelial repopulation $[82,83]$. The amniotic membrane secretes several growth factors such as hepatocyte growth factor, basic fibroblast growth factor, and transforming growth factor $\beta[84,85]$. Amniotic membrane is suggested to exert its effects by suppressing inflammation and scarring [86]. There is currently a discussion over whether amniotic membrane should be deepithelialized/denuded prior to culture, or if this substrate should remain intact. It has been reported that native, intact amniotic membrane comprise higher levels of growth factors compared to denuded amniotic membrane [87].

Amniotic membrane is the most common culture substrate for CAOMECS, and has been used in 15 clinical, three animal, and six in vitro studies (Table 1). With one exception [43], the amniotic membrane was denuded, i.e., the single layer of epithelial cells on the amniotic membrane was removed (Table 1). In the studies using amniotic membrane as a substrate for cultured CAOMECS, cell suspension [28-30,32,35,37,39,42,45-47,49-51,56-58,61-63] was applied in all studies, except four using the explant method $[40,43,59,60]$. The number of fabricated, stratified epithelial cell layers varied from two [56] to 10 [32]. Oral mucosal epithelial cells were normally cultivated between two to three weeks; however, the culture time varied between seven [62] and 28 [63] days. The most frequently used culture medium with added supplements was Dulbecco's Modified Eagle Medium (DMEM:F12) [28-30,35,39,40,42,43,46,47,49-51,56-61,63], followed by keratinocyte growth medium (KGM) [37,45] and supplemented hormonal epithelial medium (SHEM) [32,62] (Table 1). Murine fibroblasts (3T3 strain) were used in all but three studies $[40,43,56]$. Most of the culture protocols exposed the cells to air-lifting (lowering the level of the culture medium to allow the cells to be cultured at the air-liquid interface), including clinical [28,30,37,42,43,45,47,49-51], animal [57,58], and in vitro studies $[35,59,60,63]$ (Table 1). Fetal bovine serum (FBS) $[29,30,37,47,57-59,61-63]$ and fetal calf serum (FCS) $[28,32,39,42,56,60]$ were broadly used; however, six studies used human autologous serum (HAS) $[28,43,45,46,49,50]$ in an attempt to minimize/avoid the use of animal derived components (Table 1).

Oral mucosal epithelial cells cultivated on amniotic membrane exhibited multilayered, stratified epithelium and appeared very similar to a normal corneal epithelium (Table 1). The presence of non-keratinized, stratified-specific keratins $\mathrm{K} 3$ and K4/K13 was detected by immunohistochemistry, reverse transcription polymerase chain reaction, and Western blotting (Table 1). The expression of p63, a marker for undifferentiated cells, was reported in 33\% (8/24) of the studies (Table 4). Using transmission electron microscopy it was demonstrated that the cultivated oral epithelial sheet had junctional contacts, such as desmosomes, hemidesmosomes, and tight junctions, which were almost identical to those of normal corneal epithelial cells $[30,56,60,62]$.

\section{Culture of Oral Mucosal Epithelial Cells on Temperature- Responsive Surfaces}

In order to avoid the use of allogenic bacteria [53,67] and animal derived [52] components in the cornea-engineered constructs, carrier-free epithelial cell sheets using temperature-responsive culture dishes have been developed $[31,88,89]$. The modified surfaces transition between hydrophilic and hydrophobic states-depending on the temperature-by covalently immobilizing the temperature-responsive polymer poly( $N$-isopropylacrylamide) onto commercially available tissue culture wells. Under in vitro culture conditions at $37^{\circ} \mathrm{C}$, numerous cell types adhere and proliferate similarly to those of normal tissue culture polystyrene. By reducing the temperature to $20{ }^{\circ} \mathrm{C}$, the cultured cells spontaneously detach along with their deposited extracellular matrix (ECM) without the need for proteolytic enzymes such as dispase $[89,90]$. Therefore, with temperature-responsive culture surfaces the undesirable factors inherent to some substrates can be excluded from transplantable constructs. 
Nine studies (three clinical, four animal, and two in vitro) have utilized the temperature-responsive cell-culture surfaces as a substrate for CAOMECS. In all studies the cells were applied as a cell suspension and DMEM:F12 with added supplements was used as a culture medium (Table 2). The culture time for CAOMECS in these studies ranged from 10 [69] to 28 [65] days, but was most often two weeks $[31,64,66,67,70]$. The most common nutrient used was FBS [64-66,69,70]; however, two studies utilized HAS $[67,68]$. None of the studies exposed the cells to air-lifting (Table 2). The number of fabricated cell layers varied from three [69] to eight [65]. Only one study did not use 3T3 murine fibroblasts [67]. Two studies reported the cell viability of the cultured sheets to be $86 \%$ [68] and $93 \%$ [65]. The presence of p63 in the fabricated cell sheets was reported in $78 \%(7 / 9)$ of the studies (Table 4).

Table 4. Expression of p63 in cultured autologous oral mucosal epithelial cell sheet cultivated on different substrates.

\begin{tabular}{|c|c|c|c|c|}
\hline Substrate & tal Number of Studies & $\begin{array}{l}\text { Expression of p63 } \\
\text { Not Reported }\end{array}$ & $\begin{array}{l}\text { Non-Quantitative } \\
\text { Expression of p63 } \\
\text { Reported }\end{array}$ & $\begin{array}{l}\text { Quantitative Expression } \\
\text { of p63 Reported }\end{array}$ \\
\hline Amniotic membrane & 24 & 16 studies & $\begin{array}{l}4 \text { studies: p63 expressed; } \\
1 \text { study: high expression } \\
\text { of } \Delta \text { Np63; } 2 \text { studies: high } \\
\text { expression of } p 63\end{array}$ & $\begin{array}{l}1 \text { study: } 3.0 \% \pm 1.7 \% \\
\text { of cells }\end{array}$ \\
\hline $\begin{array}{l}\text { Temperature-responsivecell-culture } \\
\text { inserts }\end{array}$ & re & 2 studies & 6 studies: p63 expressed & $\begin{array}{c}1 \text { study: } 30.7 \% \pm 7.6 \% \\
\text { of cells }\end{array}$ \\
\hline Fibrin gel & 1 & - & $\begin{array}{l}1 \text { study: high } \\
\text { expression of p63 }\end{array}$ & - \\
\hline $\begin{array}{l}\text { Collagen IV-coated culture } \\
\text { plate }\end{array}$ & 1 & - & 1 study: p63 expressed & - \\
\hline Culture plate & 4 & 2 studies & $\begin{array}{l}2 \text { studies: high } \\
\text { expression of p63 }\end{array}$ & - \\
\hline
\end{tabular}

\section{Culture of Oral Mucosal Epithelial Cells on Fibrin Substrates}

Fibrin has been broadly used as a substrate in regenerative medicine and for wound-healing [91,92]. It is easily available, assists epithelial cell growth, and its degradation can be controlled by addition of fibrinolytic components. Rama and colleagues first established the use of fibrin gels as a substrate for ocular surface reconstruction in 2001 [78]. Fibrin gel is a hemostatic compound of thrombin, fibrinogen, and calcium chloride [93]. The mixture of these components fabricates a gel that is similar to the physiological lump formed at the last stage of the coagulation cascade [94]. The gel produced by this reaction is biodegradable, non-toxic, and inhibits fibrosis, tissue necrosis, and inflammation [94-96]. In vivo, the gel is completely resorbed and ultimately replaced by matrix components such as collagen [95]. A major disadvantage with fibrin as a substrate is that it encourages angiogenesis [97]. The gel, however, is resorbed within days to weeks after transplantation [94], minimizing the effects. Sheth et al. have demonstrated that CAOMECS cultivated on fibrin gel results in production of multilayered epithelium in vitro. The fabricated cell sheets expressed keratins K3, K4, and K13 [71]. The putative epithelial progenitor cell marker p63 [98] was also highly expressed (Table 3). Sheth and associates modified the pre-existing methodology to produce a reproducible, robust gel that supports the expansion and transplantation of CAOMECS, without the need for murine 3T3 fibroblasts. Fibrin-coated culture plates have also been used as a substrate for CAOMECS [41,48] (Table 3). Both studies utilized murine 3T3 fibroblasts and DMEM:F12 with added supplements as a culture medium. Human autologous serum was used as nutrient, and the cells were exposed to air-lifting [41,48].

\section{Culture of Oral Mucosal Epithelial Cells on Collagen Substrates}

All of the previously reported culture protocols for CAOMECS use serum, and most also use feeder cells to support the stratification of the epithelial cells. Due to the risk of infections associated with murine feeder cells and non-autologous serum in the cultivation of cell sheets, Ilmarinen and 
colleagues sought other options to support the stratification of isolated CAOMECS [72]. In their in vitro study, stratified epithelium was generated on collagen IV-coated culture plates in serum-free culture conditions without using 3T3 feeder cells. The authors analyzed the functional properties of the cell sheets by transepithelial electrical resistance measurements, in addition to morphology, differentiation, and regenerative capacity. This study is the only report of a successful stratification of oral mucosal epithelium for ocular surface regeneration in the absence of serum. The results showed that, in serum-free conditions, oral mucosal epithelial cells attached to and proliferated on collagen IV-coated inserts more readily than on amniotic membrane [72]. Ilmarinen and colleagues also studied the effects of increased epidermal growth factor (EGF) concentration, as EGF is known to stimulate the growth and differentiation of a variety of epithelial tissues $[99,100]$. However, they detected no major effects on the phenotype of the cell sheets using additional EGF.

\section{Culture of Oral Mucosal Epithelial Cells on Non-Coated Culture Plates}

Four studies (three in vitro and one animal) have used non-coated, substrate-free culture plates in order to fabricate transplantable CAOMECS $[33,34,73,74]$ (Table 3). All of the studies used DMEM:F12 with added supplements as a culture medium and FBS as a nutrient, without including air-lifting. In three studies, murine $3 \mathrm{~T} 3$ feeder cells were included $[33,34,74]$. The authors reported formation of a multilayered epithelium [33,34,73], one study specifying the number of cell layers [74]. Two of the four studies confirmed the expression of $\mathrm{K} 3$ and high expression of p63 [73,74].

\section{Challenges and Future Perspectives}

Recently, a meta-analytic concise review about transplantation of CAOMECS for treating LSCD has reported a success rate of $72 \%$ [19]. In this review, the focus was on clinical features of transplants of CAOMECS over the past 10 years, including surgery and pre- and postoperative considerations. In contrast, herein we focus on cell culture methods, with particular emphasis on substrates. Moreover, in the present review we expand on both in vitro and animal studies.

A complete xenobiotic-free culture protocol has become a goal in regenerative medicine; this is to avoid the risk of transferring known and unknown microorganisms and to standardize the culture conditions. The properties of epithelial cells are dependent upon extracellular signals supplied by the cell-cell and cell-substratum interactions. Further research is warranted to develop a culture system for CAOMECS that mimics the natural environment of oral/limbal/corneal epithelial cells without the need for undefined foreign materials such as serum and feeder cells.

It is likely that the phenotype of CAOMECS affects clinical success following transplantation. Thus far, p63 is the only predictor of clinical outcome following transplantation to correct LSCD [12]. Recently, Rama et al. demonstrated that the phenotype of cultured LEC is critical to ensure successful reconstruction of the ocular surface following LSCD [12]. The authors showed that successful transplantation was achieved in $78 \%$ of patients when using cell cultures in which p63-bright cells constituted more than $3 \%$ of the total number of clonogenic cells. In contrast, successful transplantation was only seen in $11 \%$ of patients when p63-bright cells made up 3\% or less of the total number of cells. In the studies using different substrates for culture of CAOMECS, the expression of p63 varied considerably (Table 4). Few studies reported the expression of p63 when using fibrin-coated culture plates, fibrin gels, collagen-coated culture plates, and culture plates without substrate (Table 4). When comparing amniotic membrane and temperature-responsive inserts, 33\% (8/24) and 78\% (7/9) of the studies showed the expression of p63, respectively (Table 4). The quantitative expression of p63 was generally poorly reported; thus, more research is warranted with quantification of phenotypic data.

The use of culture inserts with autologous serum has also been shown to facilitate the stratification of oral mucosal epithelial cells in the absence of 3T3 feeders [67]. Kolli et al. found that autologous serum was superior to FCS in generating an undifferentiated epithelium [43], and in another study the porcine trypsin was replaced with xeno-free trypsin with successful outcomes [61]. Hirayama et al. [41] showed that transplantation of a substrate-free cell sheet resulted in significantly better results than 
engrafting oral mucosal cells cultured on an amniotic membrane. The improvements were significantly higher graft survival rate, better visual acuity $(1,3,6$, and 12 months postoperatively), and reduction of neovascularization (12 months postoperatively) [41]. Furthermore, except collagen IV-coated culture plate, this review demonstrates that the use of different methods and substrates for culture of CAOMECS did not appear to have any effect on the number of cell layers generated (Table 5).

Table 5. Overall Effect of Different Culture Methods and Substrates for Cultured Autologous Oral Mucosal Epithelial Cell Sheet.

\begin{tabular}{|c|c|c|c|c|c|c|c|}
\hline Substrate/Method & Air-lifting & $\underset{\text { Nutrient }}{\text { Animal-derived }}$ & $\begin{array}{c}\text { Use of } \\
3 \mathrm{~T} 3\end{array}$ & $\begin{array}{l}\text { Serum-free } \\
\text { Medium }\end{array}$ & Viability & Morphology & $\begin{array}{c}\text { Phenotype } \\
\text { (Expression } \\
\text { of p63) }\end{array}$ \\
\hline $\begin{array}{l}\text { Amniotic } \\
\text { membrane }\end{array}$ & $17 / 24$ & $16 / 24$ & $21 / 24$ & $0 / 24$ & $>98 \%(1)$ & $\begin{array}{c}4.2 \text { cell } \\
\text { layers }(15)\end{array}$ & ++ \\
\hline $\begin{array}{l}\text { Temperature-responsive } \\
\text { cell-culture inserts }\end{array}$ & $0 / 9$ & $5 / 9$ & $8 / 9$ & $0 / 9$ & $86 \%-93 \%(2)$ & $\begin{array}{c}4.3 \text { cell } \\
\text { layers }(6)\end{array}$ & ++ \\
\hline $\begin{array}{l}\text { Fibrin-coated } \\
\text { culture plate }\end{array}$ & $2 / 2$ & $0 / 2$ & $2 / 2$ & $0 / 2$ & & $\begin{array}{c}5-6 \text { cell } \\
\text { layers }(2)\end{array}$ & - \\
\hline $\begin{array}{l}\text { Collagen IV-coated } \\
\text { culture plate }\end{array}$ & $1 / 1$ & $0 / 3$ & $0 / 1$ & $1 / 1$ & - & $\begin{array}{l}4-12 \text { cell } \\
\text { layers (1) }\end{array}$ & + \\
\hline Culture plate & $0 / 4$ & $4 / 4$ & $3 / 4$ & $0 / 4$ & - & $\begin{array}{c}2-6 \text { cell } \\
\text { layers (1) }\end{array}$ & +++ \\
\hline
\end{tabular}

Number of studies using different culture parameters is presented in the Table; - , indicates not reported;

+ , low expression of p63; ++, moderate expression of p63; +++, high expression of p63.

Due to the lack of mechanical strength provided by various culture substrates, transplantation of substrate-free cell sheets can be challenging. Hence, methods to enhance the strength and durability of the epithelial cell sheets should be further explored. Using the air-lifting technique, originally developed to formulate skin cell culture sheets for transplantation, the mechanical strength of epithelial cell sheets can be increased. The present review reveals that only $48.8 \%$ of the studies applied the air-lifting method (Tables 1-3). Interestingly, the majority of studies using amniotic membrane (71\%) did utilize air-lifting, while none of the studies with temperature-responsive surfaces applied this method (Table 5). Arguments for air-lifting include the promotion of migration [101], proliferation [101], epithelial stratification [101], and increased barrier function of LEC [102]. Arguments against air-lifting include induction of squamous metaplasia [103], gradual loss of stem cells [104], and differentiation of LEC [104,105]. Until 2010, the clinical implications of increased differentiation of transplanted cells in corneal reconstruction were unknown. This changed when Rama and colleagues demonstrated the critical importance for clinical success of a substantial, putative stem cell population within the cultured cells [12]. It is yet to be investigated whether the potential advantages of air-lifting outweigh the disadvantages in corneal regeneration using CAOMECS.

\section{Conclusions}

Most culture protocols for CAOMECS used amniotic membrane as a substrate and included the xenogeneic components FBS and murine $3 \mathrm{~T} 3$ fibroblasts. However, it has been demonstrated that tissue-engineered epithelial cell sheet grafts can be successfully fabricated using temperature-responsive culture surfaces and autologous serum. More studies on how various substrates and other culture parameters affect the cell sheet, with special emphasis on the phenotype, are warranted. Furthermore, it is important to focus on cell culture methods using xenobiotic-free conditions.

Acknowledgments: The authors would like to thank Astrid Østerud, Department of Medical Biochemistry, Oslo University Hospital, Oslo, and Catherine Jackson at Department of Medical Biochemistry. Funding received from Department of Oral Biology, Faculty of Dentistry, University of Oslo and Department of Medical Biochemistry, Oslo University Hospital, Oslo, Norway is acknowledged.

Author Contributions: Tor Paaske Utheim, Øygunn Aass Utheim and Amer Sehic searched and identified the literature; Tor Paaske Utheim and Amer Sehic analyzed the data; All wrote the paper. 
Conflicts of Interest: The authors declare no conflict of interest.

\section{References}

1. Land, M.F.; Fernald, R.D. The evolution of eyes. Ann. Rev. Neurosci. 1992, 15, 1-29. [CrossRef] [PubMed]

2. Utheim, T.P. Limbal epithelial cell therapy: Past, present, and future. Methods Mol. Biol. 2013, 1014, 3-43. [PubMed]

3. Cotsarelis, G.; Cheng, S.Z.; Dong, G.; Sun, T.T.; Lavker, R.M. Existence of slow-cycling limbal epithelial basal cells that can be preferentially stimulated to proliferate: Implications on epithelial stem cells. Cell 1989, 57, 201-209. [CrossRef]

4. Davanger, M.; Evensen, A. Role of the pericorneal papillary structure in renewal of corneal epithelium. Nature 1971, 229, 560-561. [CrossRef] [PubMed]

5. Shortt, A.J.; Secker, G.A.; Munro, P.M.; Khaw, P.T.; Tuft, S.J.; Daniels, J.T. Characterization of the limbal epithelial stem cell niche: Novel imaging techniques permit in vivo observation and targeted biopsy of limbal epithelial stem cells. Stem cells 2007, 25, 1402-1409. [CrossRef] [PubMed]

6. Dua, H.S.; Shanmuganathan, V.A.; Powell-Richards, A.O.; Tighe, P.J.; Joseph, A. Limbal epithelial crypts: A novel anatomical structure and a putative limbal stem cell niche. Br. J. Ophthalmol. 2005, 89, 529-532. [CrossRef] [PubMed]

7. Modjtahedi, B.S.; Eliott, D. Vitreoretinal complications of the boston keratoprosthesis. Semin. Ophthalmol. 2014, 29, 338-348. [CrossRef] [PubMed]

8. Sehic, A.; Utheim, O.A.; Ommundsen, K.; Utheim, T.P. Pre-clinical cell-based therapy for limbal stem cell deficiency. J. Funct. Biomater. 2015, 6, 863-888. [CrossRef] [PubMed]

9. Kenyon, K.R.; Tseng, S.C. Limbal autograft transplantation for ocular surface disorders. Ophthalmol. 1989, 96, 709-722.

10. Jenkins, C.; Tuft, S.; Liu, C.; Buckley, R. Limbal transplantation in the management of chronic contact-lens-associated epitheliopathy. Eye 1993, 7, 629-633. [CrossRef] [PubMed]

11. Pellegrini, G.; Traverso, C.E.; Franzi, A.T.; Zingirian, M.; Cancedda, R.; de Luca, M. Long-term restoration of damaged corneal surfaces with autologous cultivated corneal epithelium. Lancet 1997, 349, 990-993. [CrossRef]

12. Rama, P.; Matuska, S.; Paganoni, G.; Spinelli, A.; de Luca, M.; Pellegrini, G. Limbal stem-cell therapy and long-term corneal regeneration. New Engl. J. Med. 2010, 363, 147-155. [CrossRef] [PubMed]

13. Nakamura, T.; Sotozono, C.; Bentley, A.J.; Mano, S.; Inatomi, T.; Koizumi, N.; Fullwood, N.J.; Kinoshita, S. Long-term phenotypic study after allogeneic cultivated corneal limbal epithelial transplantation for severe ocular surface diseases. Ophthalmology 2010, 117, 2247-2254. [CrossRef] [PubMed]

14. Kolli, S.; Ahmad, S.; Lako, M.; Figueiredo, F. Successful clinical implementation of corneal epithelial stem cell therapy for treatment of unilateral limbal stem cell deficiency. Stem cells 2010, 28, 597-610. [CrossRef] [PubMed]

15. Shortt, A.J.; Secker, G.A.; Rajan, M.S.; Meligonis, G.; Dart, J.K.; Tuft, S.J.; Daniels, J.T. Ex vivo expansion and transplantation of limbal epithelial stem cells. Ophthalmology 2008, 115, 1989-1997. [CrossRef] [PubMed]

16. Nakamura, T.; Inatomi, T.; Sotozono, C.; Ang, L.P.; Koizumi, N.; Yokoi, N.; Kinoshita, S. Transplantation of autologous serum-derived cultivated corneal epithelial equivalents for the treatment of severe ocular surface disease. Ophthalmology 2006, 113, 1765-1772. [CrossRef] [PubMed]

17. Koizumi, N.; Inatomi, T.; Suzuki, T.; Sotozono, C.; Kinoshita, S. Cultivated corneal epithelial stem cell transplantation in ocular surface disorders. Ophthalmology 2001, 108, 1569-1574. [CrossRef]

18. Tsai, R.J.; Li, L.M.; Chen, J.K. Reconstruction of damaged corneas by transplantation of autologous limbal epithelial cells. New Engl. J. Med. 2000, 343, 86-93. [CrossRef] [PubMed]

19. Utheim, T.P. Concise review: Transplantation of cultured oral mucosal epithelial cells for treating limbal stem cell deficiency-current status and future perspectives. Stem Cells 2015, 33, 1685-1695. [CrossRef] [PubMed]

20. Homma, R.; Yoshikawa, H.; Takeno, M.; Kurokawa, M.S.; Masuda, C.; Takada, E.; Tsubota, K.; Ueno, S.; Suzuki, N. Induction of epithelial progenitors in vitro from mouse embryonic stem cells and application for reconstruction of damaged cornea in mice. Investig. Ophthalmol. Vis. Sci. 2004, 45, 4320-4326. [CrossRef] [PubMed] 
21. Tanioka, H.; Kawasaki, S.; Yamasaki, K.; Ang, L.P.; Koizumi, N.; Nakamura, T.; Yokoi, N.; Komuro, A.; Inatomi, T.; Kinoshita, S. Establishment of a cultivated human conjunctival epithelium as an alternative tissue source for autologous corneal epithelial transplantation. Investig. Ophthalmol. Vis. Sci. 2006, 47, 3820-3827. [CrossRef] [PubMed]

22. Yang, X.; Qu, L.; Wang, X.; Zhao, M.; Li, W.; Hua, J.; Shi, M.; Moldovan, N.; Wang, H.; Dou, Z. Plasticity of epidermal adult stem cells derived from adult goat ear skin. Mol. Reprod. Dev. 2007, 74, 386-396. [CrossRef] [PubMed]

23. Monteiro, B.G.; Serafim, R.C.; Melo, G.B.; Silva, M.C.; Lizier, N.F.; Maranduba, C.M.; Smith, R.L.; Kerkis, A.; Cerruti, H.; Gomes, J.A.; et al. Human immature dental pulp stem cells share key characteristic features with limbal stem cells. Cell Prolif. 2009, 42, 587-594. [CrossRef] [PubMed]

24. Ma, Y.; Xu, Y.; Xiao, Z.; Yang, W.; Zhang, C.; Song, E.; Du, Y.; Li, L. Reconstruction of chemically burned rat corneal surface by bone marrow-derived human mesenchymal stem cells. Stem Cells 2006, 24, 315-321. [CrossRef] [PubMed]

25. Meyer-Blazejewska, E.A.; Call, M.K.; Yamanaka, O.; Liu, H.; Schlotzer-Schrehardt, U.; Kruse, F.E.; Kao, W.W. From hair to cornea: Towards the therapeutic use of hair follicle-derived stem cells in the treatment of limbal stem cell deficiency. Stem Cells 2010, 29, 57-66. [CrossRef] [PubMed]

26. Reza, H.M.; Ng, B.Y.; Gimeno, F.L.; Phan, T.T.; Ang, L.P. Umbilical cord lining stem cells as a novel and promising source for ocular surface regeneration. Stem Cell Rev. 2011, 7, 935-947. [CrossRef] [PubMed]

27. Lin, K.J.; Loi, M.X.; Lien, G.S.; Cheng, C.F.; Pao, H.Y.; Chang, Y.C.; Ji, A.T.; Ho, J.H. Topical administration of orbital fat-derived stem cells promotes corneal tissue regeneration. Stem Cell Res. Ther. 2013, 4. [CrossRef] [PubMed]

28. Inatomi, T.; Nakamura, T.; Koizumi, N.; Sotozono, C.; Yokoi, N.; Kinoshita, S. Midterm results on ocular surface reconstruction using cultivated autologous oral mucosal epithelial transplantation. Am. J. Ophthalmol. 2006, 141, 267-275. [CrossRef] [PubMed]

29. Ma, D.H.; Kuo, M.T.; Tsai, Y.J.; Chen, H.C.; Chen, X.L.; Wang, S.F.; Li, L.; Hsiao, C.H.; Lin, K.K. Transplantation of cultivated oral mucosal epithelial cells for severe corneal burn. Eye 2009, 23, 1442-1450. [CrossRef] [PubMed]

30. Nakamura, T.; Inatomi, T.; Sotozono, C.; Amemiya, T.; Kanamura, N.; Kinoshita, S. Transplantation of cultivated autologous oral mucosal epithelial cells in patients with severe ocular surface disorders. Br. J. Ophthalmol. 2004, 88, 1280-1284. [CrossRef] [PubMed]

31. Nishida, K.; Yamato, M.; Hayashida, Y.; Watanabe, K.; Yamamoto, K.; Adachi, E.; Nagai, S.; Kikuchi, A.; Maeda, N.; Watanabe, H.; et al. Corneal reconstruction with tissue-engineered cell sheets composed of autologous oral mucosal epithelium. Engl. J. Med. 2004, 351, 1187-1196. [CrossRef] [PubMed]

32. Chen, H.C.; Yeh, L.K.; Tsai, Y.J.; Lai, C.H.; Chen, C.C.; Lai, J.Y.; Sun, C.C.; Chang, G.; Hwang, T.L.; Chen, J.K.; et al. Expression of angiogenesis-related factors in human corneas after cultivated oral mucosal epithelial transplantation. Investig. Ophthalmol. Vis. Sci. 2012, 53, 5615-5623. [CrossRef] [PubMed]

33. Kanayama, S.; Nishida, K.; Yamato, M.; Hayashi, R.; Maeda, N.; Okano, T.; Tano, Y. Analysis of soluble vascular endothelial growth factor receptor-1 secreted from cultured corneal and oral mucosal epithelial cell sheets in vitro. Br. J. Ophthalmol. 2009, 93, 263-267. [CrossRef] [PubMed]

34. Kanayama, S.; Nishida, K.; Yamato, M.; Hayashi, R.; Sugiyama, H.; Soma, T.; Maeda, N.; Okano, T.; Tano, Y. Analysis of angiogenesis induced by cultured corneal and oral mucosal epithelial cell sheets in vitro. Exp. Eye Res. 2007, 85, 772-781. [CrossRef] [PubMed]

35. Sekiyama, E.; Nakamura, T.; Kawasaki, S.; Sogabe, H.; Kinoshita, S. Different expression of angiogenesis-related factors between human cultivated corneal and oral epithelial sheets. Exp. Eye Res. 2006, 83, 741-746. [CrossRef] [PubMed]

36. Lim, P.; Fuchsluger, T.A.; Jurkunas, U.V. Limbal stem cell deficiency and corneal neovascularization. Semin. Ophthalmol. 2009, 24, 139-148. [CrossRef] [PubMed]

37. Ang, L.P.; Nakamura, T.; Inatomi, T.; Sotozono, C.; Koizumi, N.; Yokoi, N.; Kinoshita, S. Autologous serum-derived cultivated oral epithelial transplants for severe ocular surface disease. Arch. Ophthalmol. 2006, 124, 1543-1551. [CrossRef] [PubMed]

38. Burillon, C.; Huot, L.; Justin, V.; Nataf, S.; Chapuis, F.; Decullier, E.; Damour, O. Cultured autologous oral mucosal epithelial cell sheet (CAOMECS) transplantation for the treatment of corneal limbal epithelial stem cell deficiency. Investig. Ophthalmol. Vis. Sci. 2012, 53, 1325-1331. [CrossRef] [PubMed] 
39. Chen, H.C.; Chen, H.L.; Lai, J.Y.; Chen, C.C.; Tsai, Y.J.; Kuo, M.T.; Chu, P.H.; Sun, C.C.; Chen, J.K.; Ma, D.H. Persistence of transplanted oral mucosal epithelial cells in human cornea. Investig. Ophthalmol. Vis. Sci. 2009, 50, 4660-4668. [CrossRef] [PubMed]

40. Gaddipati, S.; Muralidhar, R.; Sangwan, V.S.; Mariappan, I.; Vemuganti, G.K.; Balasubramanian, D. Oral epithelial cells transplanted on to corneal surface tend to adapt to the ocular phenotype. Indian J. Ophthalmol. 2014, 62, 644-648. [PubMed]

41. Hirayama, M.; Satake, Y.; Higa, K.; Yamaguchi, T.; Shimazaki, J. Transplantation of cultivated oral mucosal epithelium prepared in fibrin-coated culture dishes. Investig. Ophthalmol. Vis. Sci. 2012, 53, 1602-1609. [CrossRef] [PubMed]

42. Inatomi, T.; Nakamura, T.; Kojyo, M.; Koizumi, N.; Sotozono, C.; Kinoshita, S. Ocular surface reconstruction with combination of cultivated autologous oral mucosal epithelial transplantation and penetrating keratoplasty. Am. J. Ophthalmol. 2006, 142, 757-764. [CrossRef] [PubMed]

43. Kolli, S.; Ahmad, S.; Mudhar, H.S.; Meeny, A.; Lako, M.; Figueiredo, F.C. Successful application of ex vivo expanded human autologous oral mucosal epithelium for the treatment of total bilateral limbal stem cell deficiency. Stem Cells 2014, 32, 2135-2146. [CrossRef] [PubMed]

44. Nakamura, T.; Inatomi, T.; Cooper, L.J.; Rigby, H.; Fullwood, N.J.; Kinoshita, S. Phenotypic investigation of human eyes with transplanted autologous cultivated oral mucosal epithelial sheets for severe ocular surface diseases. Ophthalmology 2007, 114, 1080-1088. [CrossRef] [PubMed]

45. Nakamura, T.; Takeda, K.; Inatomi, T.; Sotozono, C.; Kinoshita, S. Long-term results of autologous cultivated oral mucosal epithelial transplantation in the scar phase of severe ocular surface disorders. Br. J. Ophthalmol. 2011, 95, 942-946. [CrossRef] [PubMed]

46. Priya, C.G.; Arpitha, P.; Vaishali, S.; Prajna, N.V.; Usha, K.; Sheetal, K.; Muthukkaruppan, V. Adult human buccal epithelial stem cells: Identification, ex vivo expansion, and transplantation for corneal surface reconstruction. Eye 2011, 25, 1641-1649. [CrossRef] [PubMed]

47. Satake, Y.; Dogru, M.; Yamane, G.Y.; Kinoshita, S.; Tsubota, K.; Shimazaki, J. Barrier function and cytologic features of the ocular surface epithelium after autologous cultivated oral mucosal epithelial transplantation. Arch. Ophthalmol. 2008, 126, 23-28. [CrossRef] [PubMed]

48. Satake, Y.; Higa, K.; Tsubota, K.; Shimazaki, J. Long-term outcome of cultivated oral mucosal epithelial sheet transplantation in treatment of total limbal stem cell deficiency. Ophthalmology 2011, 118, 1524-1530. [CrossRef] [PubMed]

49. Sotozono, C.; Inatomi, T.; Nakamura, T.; Koizumi, N.; Yokoi, N.; Ueta, M.; Matsuyama, K.; Kaneda, H.; Fukushima, M.; Kinoshita, S. Cultivated oral mucosal epithelial transplantation for persistent epithelial defect in severe ocular surface diseases with acute inflammatory activity. Acta Ophthalmol. 2014, 92, e447-e453. [CrossRef] [PubMed]

50. Sotozono, C.; Inatomi, T.; Nakamura, T.; Koizumi, N.; Yokoi, N.; Ueta, M.; Matsuyama, K.; Miyakoda, K.; Kaneda, H.; Fukushima, M.; et al. Visual improvement after cultivated oral mucosal epithelial transplantation. Ophthalmology 2013, 120, 193-200. [CrossRef] [PubMed]

51. Takeda, K.; Nakamura, T.; Inatomi, T.; Sotozono, C.; Watanabe, A.; Kinoshita, S. Ocular surface reconstruction using the combination of autologous cultivated oral mucosal epithelial transplantation and eyelid surgery for severe ocular surface disease. Am. J. Ophthalmo. 2011, 152, 195-201. [CrossRef] [PubMed]

52. Rheinwald, J.G.; Green, H. Serial cultivation of strains of human epidermal keratinocytes: The formation of keratinizing colonies from single cells. Cell 1975, 6, 331-343. [CrossRef]

53. Green, H.; Kehinde, O.; Thomas, J. Growth of cultured human epidermal cells into multiple epithelia suitable for grafting. Proc. Natl. Acad. Sci. USA 1979, 76, 5665-5668. [CrossRef] [PubMed]

54. Mariappan, I.; Maddileti, S.; Savy, S.; Tiwari, S.; Gaddipati, S.; Fatima, A.; Sangwan, V.S.; Balasubramanian, D.; Vemuganti, G.K. In vitro culture and expansion of human limbal epithelial cells. Nat. Protoc. 2010, 5, 1470-1479. [CrossRef] [PubMed]

55. Martin, M.J.; Muotri, A.; Gage, F.; Varki, A. Human embryonic stem cells express an immunogenic nonhuman sialic acid. Nat. Med. 2005, 11, 228-232. [CrossRef] [PubMed]

56. Madhira, S.L.; Vemuganti, G.; Bhaduri, A.; Gaddipati, S.; Sangwan, V.S.; Ghanekar, Y. Culture and characterization of oral mucosal epithelial cells on human amniotic membrane for ocular surface reconstruction. Mol. Vis. 2008, 14, 189-196. [PubMed] 
57. Nakamura, T.; Endo, K.; Cooper, L.J.; Fullwood, N.J.; Tanifuji, N.; Tsuzuki, M.; Koizumi, N.; Inatomi, T.; Sano, Y.; Kinoshita, S. The successful culture and autologous transplantation of rabbit oral mucosal epithelial cells on amniotic membrane. Investig. Ophthalmol. Vis. Sci. 2003, 44, 106-116. [CrossRef]

58. Nakamura, T.; Kinoshita, S. Ocular surface reconstruction using cultivated mucosal epithelial stem cells. Cornea 2003, 22, S75-S80. [CrossRef] [PubMed]

59. Promprasit, D.; Bumroongkit, K.; Tocharus, C.; Mevatee, U.; Tananuvat, N. Cultivation and phenotypic characterization of rabbit epithelial cells expanded ex vivo from fresh and cryopreserved limbal and oral mucosal explants. Curr. Eye Res. 2014, 1-8.

60. Sen, S.; Sharma, S.; Gupta, A.; Gupta, N.; Singh, H.; Roychoudhury, A.; Mohanty, S.; Sen, S.; Nag, T.C.; Tandon, R. Molecular characterization of explant cultured human oral mucosal epithelial cells. Investig. Ophthalmol. Vis. Sci. 2011, 52, 9548-9554. [CrossRef] [PubMed]

61. Sharma, S.M.; Fuchsluger, T.; Ahmad, S.; Katikireddy, K.R.; Armant, M.; Dana, R.; Jurkunas, U.V. Comparative analysis of human-derived feeder layers with 3T3 fibroblasts for the ex vivo expansion of human limbal and oral epithelium. Stem cell Rev. 2012, 8, 696-705. [CrossRef] [PubMed]

62. Shimazaki, J.; Higa, K.; Kato, N.; Satake, Y. Barrier function of cultivated limbal and oral mucosal epithelial cell sheets. Investig. Ophthalmol. Vis. Sci. 2009, 50, 5672-5680. [CrossRef] [PubMed]

63. Yokoo, S.; Yamagami, S.; Mimura, T.; Amano, S.; Saijo, H.; Mori, Y.; Takato, T. UV absorption in human oral mucosal epithelial sheets for ocular surface reconstruction. Ophthalmic Res. 2006, 38, 350-354. [CrossRef] [PubMed]

64. Bardag-Gorce, F.; Oliva, J.; Wood, A.; Hoft, R.; Pan, D.; Thropay, J.; Makalinao, A.; French, S.W.; Niihara, Y. Carrier-free cultured autologous oral mucosa epithelial cell sheet (CAOMECS) for corneal epithelium reconstruction: A histological study. Ocul. Surf. 2015, 13, 150-163. [CrossRef] [PubMed]

65. Hayashi, R.; Yamato, M.; Takayanagi, H.; Oie, Y.; Kubota, A.; Hori, Y.; Okano, T.; Nishida, K. Validation system of tissue-engineered epithelial cell sheets for corneal regenerative medicine. Tissue Eng. Part C Methods 2010, 16, 553-560. [CrossRef] [PubMed]

66. Hayashida, Y.; Nishida, K.; Yamato, M.; Watanabe, K.; Maeda, N.; Watanabe, H.; Kikuchi, A.; Okano, T.; Tano, Y. Ocular surface reconstruction using autologous rabbit oral mucosal epithelial sheets fabricated ex vivo on a temperature-responsive culture surface. Investig. Ophthalmol. Vis. Sci. 2005, 46, 1632-1639. [CrossRef] [PubMed]

67. Murakami, D.; Yamato, M.; Nishida, K.; Ohki, T.; Takagi, R.; Yang, J.; Namiki, H.; Okano, T. Fabrication of transplantable human oral mucosal epithelial cell sheets using temperature-responsive culture inserts without feeder layer cells. J. Artif. Organs Off. J. Jpn. Soc. Artif. Organs 2006, 9, 185-191. [CrossRef] [PubMed]

68. Oie, Y.; Hayashi, R.; Takagi, R.; Yamato, M.; Takayanagi, H.; Tano, Y.; Nishida, K. A novel method of culturing human oral mucosal epithelial cell sheet using post-mitotic human dermal fibroblast feeder cells and modified keratinocyte culture medium for ocular surface reconstruction. Br. J. Ophthalmol. 2010, 94, 1244-1250. [CrossRef] [PubMed]

69. Soma, T.; Hayashi, R.; Sugiyama, H.; Tsujikawa, M.; Kanayama, S.; Oie, Y.; Nishida, K. Maintenance and distribution of epithelial stem/progenitor cells after corneal reconstruction using oral mucosal epithelial cell sheets. PloS One 2014, 9. [CrossRef] [PubMed]

70. Sugiyama, H.; Yamato, M.; Nishida, K.; Okano, T. Evidence of the survival of ectopically transplanted oral mucosal epithelial stem cells after repeated wounding of cornea. Mol. Ther. J. Am. Soc. Gene Ther. 2014, 22, 1544-1555. [CrossRef] [PubMed]

71. Sheth, R.; Neale, M.H.; Shortt, A.J.; Massie, I.; Vernon, A.J.; Daniels, J.T. Culture and characterization of oral mucosal epithelial cells on a fibrin gel for ocular surface reconstruction. Curr. Eye Res. 2014, 1-11. [CrossRef] [PubMed]

72. Ilmarinen, T.; Laine, J.; Juuti-Uusitalo, K.; Numminen, J.; Seppanen-Suuronen, R.; Uusitalo, H.; Skottman, H. Towards a defined, serum- and feeder-free culture of stratified human oral mucosal epithelium for ocular surface reconstruction. Acta Ophthalmol. 2013, 91, 744-750. [CrossRef] [PubMed]

73. Krishnan, S.; Iyer, G.K.; Krishnakumar, S. Culture \& characterisation of limbal epithelial cells \& oral mucosal cells. Indian J. Med. Res. 2010, 131, 422-428. [PubMed]

74. Hyun, D.W.; Kim, Y.H.; Koh, A.Y.; Lee, H.J.; Wee, W.R.; Jeon, S.; Kim, M.K. Characterization of biomaterial-free cell sheets cultured from human oral mucosal epithelial cells. J. Tissue Eng. Regener. Med. 2014. [CrossRef] [PubMed] 
75. Schwab, I.R.; Reyes, M.; Isseroff, R.R. Successful transplantation of bioengineered tissue replacements in patients with ocular surface disease. Cornea 2000, 19, 421-426. [CrossRef] [PubMed]

76. Schwab, I.R. Cultured corneal epithelia for ocular surface disease. Trans. Am. Ophthalmol. Soc. 1999, 97, 891-986. [PubMed]

77. Pellegrini, G.; Ranno, R.; Stracuzzi, G.; Bondanza, S.; Guerra, L.; Zambruno, G.; Micali, G.; de Luca, M. The control of epidermal stem cells (holoclones) in the treatment of massive full-thickness burns with autologous keratinocytes cultured on fibrin. Transplantation 1999, 68, 868-879. [CrossRef] [PubMed]

78. Rama, P.; Bonini, S.; Lambiase, A.; Golisano, O.; Paterna, P.; de Luca, M.; Pellegrini, G. Autologous fibrin-cultured limbal stem cells permanently restore the corneal surface of patients with total limbal stem cell deficiency. Transplantation 2001, 72, 1478-1485. [CrossRef] [PubMed]

79. Han, B.; Schwab, I.R.; Madsen, T.K.; Isseroff, R.R. A fibrin-based bioengineered ocular surface with human corneal epithelial stem cells. Cornea 2002, 21, 505-510. [CrossRef] [PubMed]

80. De Rötth, A. Plastic repair of conjunctival defects with fetal membrane. Arch. Ophthalmol. 1940, 23, 522-525. [CrossRef]

81. Sorsby, A.; Symons, H.M. Amniotic membrane grafts in caustic burns of the eye (burns of the second degree). Br. J. Ophthalmol. 1946, 30, 337-345. [CrossRef] [PubMed]

82. Anderson, D.F.; Ellies, P.; Pires, R.T.; Tseng, S.C. Amniotic membrane transplantation for partial limbal stem cell deficiency. Br. J. Ophthalmol. 2001, 85, 567-575. [CrossRef] [PubMed]

83. Tseng, S.C.; Prabhasawat, P.; Barton, K.; Gray, T.; Meller, D. Amniotic membrane transplantation with or without limbal allografts for corneal surface reconstruction in patients with limbal stem cell deficiency. Arch. Ophthalmol. 1998, 116, 431-441. [CrossRef] [PubMed]

84. Shimazaki, J.; Shinozaki, N.; Tsubota, K. Transplantation of amniotic membrane and limbal autograft for patients with recurrent pterygium associated with symblepharon. Br. J. Ophthalmol. 1998, 82, 235-240. [CrossRef] [PubMed]

85. Sato, H.; Shimazaki, J.; Shinozaki, N.; Tsubota, K. Role of growth factors for ocular surface reconstruction after amniotic membrane transplantation. Investig. Ophthalmol. Vis. Sci. 1998, 39, 428-430.

86. Tosi, G.M.; Massaro-Giordano, M.; Caporossi, A.; Toti, P. Amniotic membrane transplantation in ocular surface disorders. J. Cell Physiol. 2005, 202, 849-851. [CrossRef] [PubMed]

87. Koizumi, N.J.; Inatomi, T.J.; Sotozono, C.J.; Fullwood, N.J.; Quantock, A.J.; Kinoshita, S. Growth factor mRNA and protein in preserved human amniotic membrane. Curr. Eye Res. 2000, 20, 173-177. [CrossRef]

88. Nishida, K.; Yamato, M.; Hayashida, Y.; Watanabe, K.; Maeda, N.; Watanabe, H.; Yamamoto, K.; Nagai, S.; Kikuchi, A.; Tano, Y.; et al. Functional bioengineered corneal epithelial sheet grafts from corneal stem cells expanded ex vivo on a temperature-responsive cell culture surface. Transplantation 2004, 77, 379-385. [CrossRef] [PubMed]

89. Yamato, M.; Utsumi, M.; Kushida, A.; Konno, C.; Kikuchi, A.; Okano, T. Thermo-responsive culture dishes allow the intact harvest of multilayered keratinocyte sheets without dispase by reducing temperature. Tissue Eng. 2001, 7, 473-480. [CrossRef] [PubMed]

90. Kushida, A.; Yamato, M.; Konno, C.; Kikuchi, A.; Sakurai, Y.; Okano, T. Decrease in culture temperature releases monolayer endothelial cell sheets together with deposited fibronectin matrix from temperature-responsive culture surfaces. J. Biomed. Mater. Res. 1999, 45, 355-362. [CrossRef]

91. Dunn, C.J.; Goa, K.L. Fibrin sealant: A review of its use in surgery and endoscopy. Drugs 1999, 58, 863-886. [CrossRef] [PubMed]

92. Martinowitz, U.; Saltz, R. Fibrin sealant. Curr. Opin. Hematol. 1996, 3, 395-402. [CrossRef] [PubMed]

93. Le Guehennec, L.; Goyenvalle, E.; Aguado, E.; Pilet, P.; Spaethe, R.; Daculsi, G. Influence of calcium chloride and aprotinin in the in vivo biological performance of a composite combining biphasic calcium phosphate granules and fibrin sealant. J. Mater. Sci. Mater. Med. 2007, 18, 1489-1495. [CrossRef] [PubMed]

94. Radosevich, M.; Goubran, H.I.; Burnouf, T. Fibrin sealant: Scientific rationale, production methods, properties, and current clinical use. Vox Sang. 1997, 72, 133-143. [CrossRef] [PubMed]

95. Tuan, T.L.; Song, A.; Chang, S.; Younai, S.; Nimni, M.E. In vitro fibroplasia: Matrix contraction, cell growth, and collagen production of fibroblasts cultured in fibrin gels. Exp. Cell Res. 1996, 223, 127-134. [CrossRef] [PubMed]

96. Weisel, J.W. Fibrinogen and fibrin. Adv. Protein. Chem. 2005, 70, 247-299. [PubMed] 
97. Dvorak, H.F.; Harvey, V.S.; Estrella, P.; Brown, L.F.; McDonagh, J.; Dvorak, A.M. Fibrin containing gels induce angiogenesis. Implications for tumor stroma generation and wound healing. Lab. Invest. 1987, 57, 673-686. [PubMed]

98. Pellegrini, G.; Dellambra, E.; Golisano, O.; Martinelli, E.; Fantozzi, I.; Bondanza, S.; Ponzin, D.; McKeon, F.; de Luca, M. P63 identifies keratinocyte stem cells. Proc. Natl. Acad. Sci. USA 2001, 98, 3156-3161. [CrossRef] [PubMed]

99. Carpenter, G.; Cohen, S. Epidermal growth factor. J. Biol. Chem. 1990, 265, 7709-7712. [PubMed]

100. Herbst, R.S. Review of epidermal growth factor receptor biology. Int. J. Radiat. Oncol. Biol. Phys. 2004, 59, 21-26. [CrossRef] [PubMed]

101. Dua, H.S.; Miri, A.; Alomar, T.; Yeung, A.M.; Said, D.G. The role of limbal stem cells in corneal epithelial maintenance: Testing the dogma. Ophthalmology 2009, 116, 856-863. [CrossRef] [PubMed]

102. Kawakita, T.; Espana, E.M.; He, H.; Li, W.; Liu, C.Y.; Tseng, S.C. Intrastromal invasion by limbal epithelial cells is mediated by epithelial-mesenchymal transition activated by air exposure. Am. J. Pathol. 2005, 167, 381-393. [CrossRef]

103. Ban, Y.; Cooper, L.J.; Fullwood, N.J.; Nakamura, T.; Tsuzuki, M.; Koizumi, N.; Dota, A.; Mochida, C.; Kinoshita, S. Comparison of ultrastructure, tight junction-related protein expression and barrier function of human corneal epithelial cells cultivated on amniotic membrane with and without air-lifting. Exp. Eye Res. 2003, 76, 735-743. [CrossRef]

104. Henderson, H.W.; Collin, J.R. Mucous membrane grafting. Dev. Ophthalmol. 2008, 41, 230-242. [PubMed]

105. Meyer-Blazejewska, E.A.; Kruse, F.E.; Bitterer, K.; Meyer, C.; Hofmann-Rummelt, C.; Wunsch, P.H.; Schlotzer-Schrehardt, U. Preservation of the limbal stem cell phenotype by appropriate culture techniques. Investig. Ophthalmol. Vis. Sci. 2010, 51, 765-774. [CrossRef] [PubMed]

(C) 2016 by the authors; licensee MDPI, Basel, Switzerland. This article is an open access article distributed under the terms and conditions of the Creative Commons by Attribution (CC-BY) license (http://creativecommons.org/licenses/by/4.0/). 